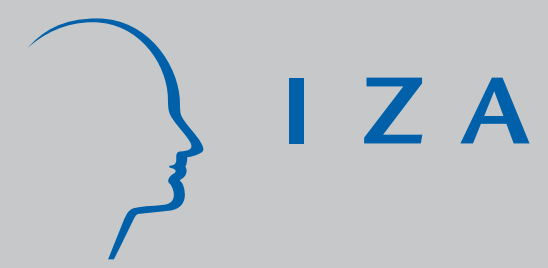

IZA DP No. 7975

Information Technologies and Provision of National Identification Cards by the Bolivian Police: Evidence from Two Randomized Natural Field Experiments

Alberto Chong

Gustavo Machicado Salas

Monica Yanez-Pagans

February 2014 


\title{
Information Technologies and Provision of National Identification Cards by the Bolivian Police: Evidence from Two Randomized Natural Field Experiments
}

\author{
Alberto Chong \\ University of Ottawa
}

Gustavo Machicado Salas

Institute for Advanced Development Studies

Monica Yanez-Pagans

World Bank and IZA

Discussion Paper No. 7975

February 2014

\author{
IZA \\ P.O. Box 7240 \\ 53072 Bonn \\ Germany \\ Phone: +49-228-3894-0 \\ Fax: +49-228-3894-180 \\ E-mail: iza@iza.org
}

Any opinions expressed here are those of the author(s) and not those of IZA. Research published in this series may include views on policy, but the institute itself takes no institutional policy positions. The IZA research network is committed to the IZA Guiding Principles of Research Integrity.

The Institute for the Study of Labor (IZA) in Bonn is a local and virtual international research center and a place of communication between science, politics and business. IZA is an independent nonprofit organization supported by Deutsche Post Foundation. The center is associated with the University of Bonn and offers a stimulating research environment through its international network, workshops and conferences, data service, project support, research visits and doctoral program. IZA engages in (i) original and internationally competitive research in all fields of labor economics, (ii) development of policy concepts, and (iii) dissemination of research results and concepts to the interested public.

IZA Discussion Papers often represent preliminary work and are circulated to encourage discussion. Citation of such a paper should account for its provisional character. A revised version may be available directly from the author. 


\section{ABSTRACT}

\section{Information Technologies and Provision of National Identification Cards by the Bolivian Police: Evidence from Two Randomized Natural Field Experiments*}

This paper investigates the potential of information technologies to improve public service delivery and empower citizens in the context of two unusual randomized natural experiments occurring within one particular bureaucratic process: the renewal of a national identification card by the Bolivian Police. The first experiment arises from the random assignment of both police officers and applicants to a manual or digital renewal process, which is identical in all aspects except that the digital renewal process makes use of information technologies as part of the renewal process. The second experiment arises by the existence of technical failures within the digital renewal process, which allows police officers to change from the digital to the manual renewal process randomly across renewal day. The efficiency of public service delivery is measured in terms of both renewal success rates (which average to a strikingly low rate of 72 percent in our sample) and time-it-takes to renew an identification card. We find that information technologies significantly improve the quality of public service delivery. Also, we find that information technologies significantly lower barriers in access to national identification cards by promoting a more equitable provision across the population. We discuss several channels through which technologies might be improving efficiency and promoting equity within this particular bureaucratic process. Overall, our findings suggest that information technologies might be achieving these goals by introducing efficiencies (such as reducing administrative shortcomings and transaction costs), and limiting the exercise of discretion by police officers within the renewal process.

JEL Classification: C93, O38, J24

Keywords: Bolivia, technologies, public service delivery, natural experiment

Corresponding author:

Monica Yanez-Pagans

Poverty Reduction and Economic Management Network

World Bank

1818 H Street, NW

Washington, DC 20433

USA

E-mail: myanezpagans@worldbank.org

\footnotetext{
*We are very grateful to Víctor Hugo Escobar, Alfonso Vargas, Wilhelm Taboada, and Boris Villarroel for their collaboration in making this study possible. For helpful discussions and comments, we thank Horacio Aguirre, Mary Arends- Kuenning, Kathy Baylis, Nestor Gandelman, Nicolás Garcette, Saweda Liverpool, Nolan Miller, Alex Winter-Nelson, and Patricia Yanez-Pagans. This project was funded and undertaken as part of the Latin American and Caribbean Research Network of the Inter-American Development Bank. The paper has been screened to insure that no confidential information is revealed.
} 


\section{Introduction}

Shortcomings in identification documents and, more generally, lack of identification documents are pervasive and widespread problems in most of the developing world. In general, the poor are at higher risk of holding invalid identification documents and, therefore, of being denied access to basic social services and marginalized. In many developing countries, identification cards are an essential document to hold a job in the formal sector, own property, receive basic social services, benefit from social transfers, carry out bank transactions, vote in elections and, more generally, to fully participate in society (Duryea, Olgiati, and Stone, 2006). Still, getting an identification card in many of these countries is a complicated process, which is generally associated with excessive bureaucracy, red tape, and corruption. Moreover, bureaucracy is intimidating to many people, especially so to the poor and those belonging to groups traditionally excluded from the mainstream. To this end, understanding how to lower barriers in access to identification cards is vital to promote more equitable access to public services by citizens.

Over the past decade, access to information technologies in developing countries has grown rapidly. Increased access to these technologies has unleashed the potential to use of them to advance development objectives and promote greater equality (Sunden and Wicander, 2006). Applications of information technologies to address development challenges have multiplied in recent years. Some examples include the use of information technologies to access price information for market participants in Peru, access to financial services through mobile banking in Kenya, and rapid damage assessment following natural disasters like the earthquake in Haiti (World Bank, 2011). However, the use of information technologies as a means to improve the quality and reach of government services has lagged behind in comparison. Information technologies significantly affect the way in which citizens and governments interact, and whether they might be effective at enhancing economic opportunities for the poor, improving delivery of services to the under-served, and enhancing government efficiency and transparency is an important and open empirical question.

Although the development community is increasingly supporting public service reforms linked to information technologies, there is little evidence about the potential of these technologies for dealing with some of the challenges to public service reform in developing countries. ${ }^{1}$ Information technologies might affect governance and public service delivery outcomes through different channels, including efficiency, effectiveness, transparency, and increased access (World Bank, 2011). Yet, the benefits arising from the use of information technologies and its mechanisms have been notoriously difficult to measure (e.g. Bresnahan and Gordon (1997), and Griliches (1998)). Most of the previous literature has looked at aggregated data or firm-level data and has looked at the effects of investments in information technologies on labor productivity measures or total factor productivity (e.g. Schreyer (2000), Colecchia and Schreyer (2001), and Stiroh (2001)). Some other studies have relied instead on growth accounting techniques, estimating the basic neoclassical production function, including information technologies as one of the production factors (e.g. Draca, Sadun, and Reenen, 2006).

\footnotetext{
${ }^{1}$ For instance, the World Bank has just released an entire report devoted to the idea of achieving development results through information technologies applications (World Bank, 2011). The flagship publication of the Inter-American Development Bank, this year, is also entirely devoted to the idea of incorporating information technologies as a tool to advance development objectives (Inter-American Development Bank, 2011).
} 
This paper investigates the potential of information technologies to improve public service delivery and empower citizens in the context of two unusual randomized natural experiments occurring within one particular bureaucratic process: the renewal of a national identification card by the Bolivian Police (ID cards from now on). ${ }^{2}$ The first natural experiment arises from the random assignment of both police officers and applicants to a manual or digital renewal process, which is identical in all aspects except that the digital process makes use of information technologies as part of the renewal process that introduce efficiencies within the process. The second experiment arises by the existence of technical failures within the digital renewal process, which allow for police officers to randomly change from the digital to the manual process across renewal day. The causal effect of information technologies on ID card provision is identified by using two different identification strategies. In the first one, we compare applicant-police officer pairs randomly assigned to each of these two renewal processes after controlling for day-of-renewal fixed effects. In the second one, we take advantage of the prevalence of technical failures, and compare instead applicant-police officers pairs randomly assigned to the digital or manual process after controlling for police officer fixed effects. The quality of public service delivery within this bureaucratic process is measured in terms of success rates at completing the renewal process and time it takes to complete the process conditional on being successful.

The results of this paper present strong evidence that the adoption of information technologies by the Police led to substantial improvements in the quality of service provided to citizens. Applicants randomly assigned to a digital renewal process are, on average, 12 percentage points more likely to complete the renewal process as compared to those randomly assigned to the manual process. Further, applicants who are able to complete the renewal process and who are randomly assigned to the digital process, take on average 31 percent less time to complete the renewal process as compared to the average time taken by those applicants who are able to complete the renewal process and who are randomly assigned to the manual process. Information technologies seem to be translating into an improvement in overall quality within this bureaucratic process by increasing efficiencies within the renewal process, including a reduction in transaction costs and an increase in accountability to citizens. More importantly, we find strong evidence that the characteristics of applicants are important predictors of the probability of successfully completing a renewal process, and the time it takes to complete it conditional on being successful. Applicants from rural areas, indigenous groups, with lower levels of education, and from lower socioeconomic strata all have lower success rates as compared to those from relatively better-off backgrounds. To the extent that we just look at ID card renewals instead of new applications, my findings are hard to reconcile with the existence of heterogeneous paperwork quality among applicants. In addition and interestingly, we find robust evidence that information technologies within this bureaucratic process are significantly lowering barriers in access to ID cards among applicants from relatively disadvantaged backgrounds and, thus, serve as effective tools at promoting equitable public service delivery within this bureaucratic process. Overall, my findings are consistent with the existence of selective enforcement of rules and disparities in service quality by police officers based on applicants characteristics, and the possibility that red tape might affect applicants differently based on their intrinsic characteristics.

The remainder of this paper is organized as follows. Section discusses the setting of the study. Section 3 describes the two natural experiments in this setting. Section 4 presents the estimation framework. Section

\footnotetext{
${ }^{2}$ National identification cards are analogous to Social Security numbers in the US.
} 
5 describes the data. Section 6 presents the experimental results. Section 7 discusses the results of the study. Section 8 concludes.

\section{Setting of the study}

In Article 27, the Organic Law of the Bolivian Police of 1985 stipulates that the Police is the entity in charge of the provision of ID cards to citizens. At the local level, the Identification Units are the bodies responsible for administering this act. In La Paz, the city where this study takes place, ID cards are issued at two Identification Units. Each of these Units is located at two distant points in the city: one is in the downtown area and one in the rich south zone. However, the jurisdiction of each office does not coincide with the neighborhood of residence, and individuals can obtain their ID cards in any of these two offices. The downtown Identification Unit is by far the largest in the city. At the time of this study, it was issuing roughly 95 percent of the total number of ID cards per day in the city — approximately 1,200 cards per day.

To renew a national ID card, an individual needs to bring a proof of identity to the Identification Unit, and pay an application fee of BS 17 (USD 2.5). Acceptable documents as proof of identity include expired ID card, birth certificate, current (i.e. not expired) driving license, military ID card, passport, school ID card, or electoral list fraud prevention card. Upon presentation of a valid proof of identity, the applicant gets randomly assigned to a renewal table at the Unit. In the downtown Identification Unit, the setting for this study, there are 41 renewal tables, each of whom has a police officer permanently assigned to it. As soon as the applicant gets to his renewal table, he needs to hand over his proof of identity and the token with the renewal table number assigned to. The police officer assigned to the table then needs to locate the vital records of the applicant, which are kept at a Vital Records Archive maintained by the Police located at the basement of the building and only accessible to police officers. Once the vital records of the applicant have been located, the last name of the applicant is called and the applicant needs then to go through a series of steps to complete the renewal process. These renewal steps include paying for the application fee at a Financial Services and Cashier Operations office, getting a photograph taken, fingerprinting and, if needed, getting marital status, occupation, and residence updated. Upon completion of all these steps, the ID card renewal process is considered completed and the card is sent for lamination. The individual then can pick up the ID card within 24 hours from the Identification Unit.

The simple administrative steps required to complete the renewal process are, in practice, a lengthy process. Renewing a national ID card in Bolivia has long been associated with red tape, bureaucratic delay, corruption, and the provision of different service quality by police officers to applicants based on their characteristics (e.g. World Bank (2000), Mansilla (2003), Quintana (2003), and Wanderley (2007)). Further, administrative shortcomings are pervasive within this process. For instance, vital records are often reported as missing. ${ }^{3}$ The Identification Unit has a poor archiving system, which is based only on the last name of the applicant, and therefore results in many missing vital records. To the extent that the Unit holds more than 1

\footnotetext{
${ }^{3}$ Other reasons why the applicants might not be able to complete the renewal process include misspelling of names (due to typing mistakes incurred by the police officers), duplicity of cards, and long waiting times.
} 
million records in its archives, and that these are all stacked in a small basement, vital records are often lost. Yet, what it is not clear is the extent to which the issue of missing vital records affects applicants randomly or is the result of a shortcoming incurred by police officers systematically. Another practice, which is believed to be quite common among police officers, is the provision of different service quality to applicants based on their observable characteristics. Police officers might not be very helpful with applicants from relatively disadvantaged backgrounds or might not call their names on a first-come first-served basis but rather at their own discretion. In practice, the prevalence of administrative shortcomings, and more generally the possibility of exercising discretion at completing some of the renewal steps, often leads to police officers being willing to accept, or implicitly asking for, extra-legal payments in order to bend some of the rules and expedite the process (United Nations Development Program,, 2006). ${ }^{4}$ All the red tape present within this process is further exacerbated by the lack of information on the steps that should be followed to renew an ID card, the overcrowding of applicants, and the poor signage at the Identification Unit.

\section{Two unique natural experiments}

Since 2006, the Police started a large effort to digitize vital records of citizens across the country. This effort was aimed both at improving the provision of ID cards to citizens and curbing electoral fraud and corruption. By the time this study took place, vital records of all citizens in the city of La Paz had been digitized, and put into a vital records dataset. This newly created dataset called for a full transformation of the renewal process. As part of this transformation process, the Identification Unit introduced a new digital renewal process, which consisted of accessing the vital records of the applicants online using a computer, filling the applicants' information online, getting the photograph taken using a digital camera connected to that computer, and getting the ID card printed out in a laser printer. That is, the digital process allowed for all of the renewal steps to be performed at the renewal table, except for the payment of the application fee. This was in sharp contrast to the old manual renewal process, which required the applicant to get his photograph taken out at a different building and pick-up his photograph at a developing film office, which was also located at a different building within the Unit. At the end of the day, however, ID cards issued under the manual and digital process were identical except for the fact that the digital ones were issued following the digital renewal process.

For a short period of time, the downtown Identification Unit in the city of La Paz was simultaneously following both the manual and digital renewal process. This existence of this dual renewal system was the result of budget constraints, which did not allow the Police to introduce these technologies in all of the 41 renewal tables at the Unit simultaneously. To avoid complaints, the Police decided to randomly assign both police officers and applicants to each one of these two renewal processes. On the one hand, police officers were randomly assigned to either one of the processes by lottery at the beginning of the transition period and remained at the same table throughout their time at the Identification Unit. On the other hand, applicants

\footnotetext{
${ }^{4}$ Extra-legal payments are usually in the order of 2 to 10 USD per ID card. This is a significant amount in Bolivia considering that the minimum monthly wage is around $92 \mathrm{USD}$, and that the median monthly wage is around 363 USD (UDAPE, 2009).
} 
were randomly assigned to each one of these two processes by the following a simple sequential rule. Upon presentation of the valid document as proof of identity, the applicant was sequentially assigned to one of the 41 renewal tables located across the Identification Unit - 23 of them issuing manual cards and 18 of them issuing digital ones. As the type of renewal was randomly allocated across police officers, the numerical correspondence of tables was completely unrelated to the type of process followed in each renewal table. Moreover, to assure that applicants did not try to change their randomly assigned renewal table number, applicants thumbnails were marked at the randomization table with election ink. This simple device, strictly enforced in practice, prevented applicants from starting a new renewal process within the same day (or couple of days until the ink had faded away) if they were not assigned to their preferred type of renewal process.

A unique feature of this study is the existence of technical failures. Technical failures affect only tables that follow a digital renewal process and occur frequently. In this setting, technical failures refer to lack of printer consumables or temporarily out-of-order computers. Roughly 19 percent of the digital tables report at least one technical failure each week. Because of the administrative procedures followed by the Police, technical failures could not be addressed the same day. So, if a computer broke down for example, it would be down for the rest of the day. Also, if a printer would ran out of toner, it would only be replaced at the end of the day. This introduced a second natural experiment in this setting. In particular, to avoid delays and overcrowding of applicants, the Police decided to allow all digital tables to continue issuing manual cards when a technical failure suddenly arose. In practice, this boiled down to allowing them to keep the old typewriter they were using during the manual system, and instructing them to switch immediately to the manual process if a technical failure arose.

Although applicants and police officers were assigned to the digital renewal process randomly as described above, it is useful to examine whether the digital renewal process is ex-post correlated with some police officer and applicant characteristics of interest. Table 1 explores this by reporting marginal effects of probit regressions for the probability of being randomized into the digital process as a function of 5 police officers, and 6 applicant characteristics. As expected, given the randomization, the magnitudes of these marginal effects are small and not jointly-significant predictors of the probability of being assigned into a digital renewal process at standard levels (joint $p$-values $0.17,0.12,0.18,0.11$, and 0.10 depending on the specification). This is reassuring and suggests that the administrative procedures put in place by the Police at the Identification Unit were closely followed and enforced in practice - at least along the observable dimensions. However, as several of these covariates (police officer tenure, police office rank, male applicant rural status, and female applicant education level) are individually significant at the 5 and 10 percent levels, we estimate the main experimental results including these covariates. The main results of the paper, however, remain largely unchanged when adding these covariates as control variables.

\section{Estimation framework}

The causal effect of information technologies, over traditional technologies, on the provision of ID cards for citizens can be estimated using the following regression model for applicant $i$ assigned to police officer $j$ 's 
renewal table on day $t$ :

$$
y_{i j t}=\alpha+\beta \text { digital }_{i j}+\omega_{t}+\xi_{i j t}
$$

where y is either: (i) indicator for whether the renewal process was successfully completed; or (ii) time it takes to complete the renewal process conditional on successfully completing it; digital is an indicator for whether the table uses a digital renewal process; $\omega$ is a vector of 28 renewal day fixed effects; and $\xi$ is a normally distributed error term independently and identically distributed over $i$ and $t$, and clustered at the police officer level.

As explained in the previous section, a unique feature of this study is the existence of technical failures. To the extent that technical failures affect renewal tables following the digital process randomly, they can be used to estimate the causal effect of information technologies on ID card provision outcomes by comparing applicant-police officer pairs randomly assigned to the digital process after controlling for police officer fixed effects. This allows controlling for unobserved heterogeneity at the police officer level in the model. Formally:

$$
y_{i j t}=\delta+\gamma \text { digital }_{i t}+\theta_{j}+\xi_{i j t}
$$

where digital is an indicator for whether the police officer follows a digital renewal process on day $t$; and $\theta$ is a vector of 41 police officer fixed effects. To the extent that we only look at renewals in this study, an important thing to highlight here also is that differential paperwork quality among applicants to complete the process should not be a source of bias in this setting. ${ }^{5}$

There are several mechanisms through which information technologies might affect renewal outcomes in this setting. First, information technologies may affect renewal success rates by reducing administrative shortcomings, reducing transaction costs, and limiting the possibility that police officers exercise discretion as far as missing vital records. Second, information technologies may affect the time it takes to complete a renewal process through two different channels. On the one hand, information technologies may increase productivity among police officers by introducing efficiencies within the process, such as accessing the vital records of the applicants online, getting the picture taken at the renewal table, etc. On the second hand, information technologies may reduce the probability that red tape affects applicants by allowing them to perform all of the renewals steps at the renewal table.

The use of information technologies might also affect renewal outcomes through the aplicants' and police officers' characteristics. First, applicant's characteristics might be important determinants of renewal outcomes. For instance, if an applicant finds it hard to navigate the renewal process steps because he is illiterate, this would translate into differential renewal outcomes based on the level of education of the applicant. Second, police officers characteristics such as age, rank, and education may be important determinants of

\footnotetext{
${ }^{5}$ We are not able to use a specification of the model that includes both police officer and renewal day fixed effects because data on technical failures from administrative records is only collected on a daily basis. This means that we do not have variation in type of renewal by police officer within day of renewal.
} 
variation in efficiency within the administrative procedures required to complete the renewal process. For instance, if the skills required to complete the process are highly correlated with police officers' characteristics, these might translate into different renewal outcomes based on police officers' characteristics. Third, police officers' tenure may affect the renewal process through a learning effect. For instance, police officers that have been working at the Identification Unit for a longer time might be more familiar with the process and, thus, be able to outperform compared to police officers recently brought into the process. To formally explore all of these hypotheses, we use the following three regression models:

$$
\begin{aligned}
& y_{i j t}=\alpha+\beta\left(\text { digital }_{i t} * A_{i}\right)+\psi \text { digital }_{i t}+\delta A_{i}+\omega_{t}+\xi_{i j} \\
& y_{i j t}=\alpha+\beta\left(\text { digital }_{i t} * A_{i}\right)+\psi \text { digital }_{i t}+\delta A_{i}+\omega_{j}+\xi_{i t} \\
& y_{i j t}=\alpha+\beta\left(\text { digital }_{i t} * P_{j}\right)+\psi \text { digital }_{i t}+\mu P_{j}+\omega_{t}+\xi_{i j}
\end{aligned}
$$

where $A_{i}$ is a vector of applicant characteristics including age, education, gender, rural status, attended private school (which serves as a proxy of social status), indigenous language spoken, and indigenous attire; and $P_{j}$ is a vector of police officer characteristics including tenure at the Identification Unit, tenure at the renewal table, rank, age, education, and gender.

\section{Data}

The data for this paper come from multiple sources and combine different methods of inquiry. The primary data collected at the applicant level include the following: (i) starting and completion renewal times; (ii) renewal table number; and (iii) basic socioeconomic and demographic characteristics. The administrative data collected at the police officer level include the following: (i) renewal table number; (ii) basic socioeconomic and demographic characteristics; and (ii) technical failures at renewal tables. All of the data were collected between October 27 and December 5, 2009.

\section{Primary data}

The primary data were collected using a very simple software specifically designed for this study. Figure 1 shows a screenshot of the software interface used for the data collection. ${ }^{6}$ The software collected basic information for the applicants including starting and completion times, renewal day, renewal table number, sex, age, rural status, education level, whether the applicant ever attended a private school, whether the applicant spoke an indigenous language, and neighborhood of residence. We also collected information on

\footnotetext{
${ }^{6}$ The software was installed in three computers located next to the randomization table, and two computers located at the exit door. All of the five computers were operated by police officers from the Identification Unit, which were unrelated to the renewal process and just hired to perform this task.
} 
indigenous attire for female applicants only, who can easily and objectively be classified across indigenousstatus by simple inspection of their clothing — which is not the case for men. ${ }^{7}$ The information on sex, age, rural status, education level, and residence was directly collected from the expired ID card. If another document was used as proof as identity, then this information was directly collected from the applicant. The information about indigenous language and private school status was self-reported by applicants, and the information about indigenous attire was collected from direct observation.

\section{Administrative data}

The basic socioeconomic and demographic characteristics of police officers were collected from administrative records provided by the Identification Unit. These data included sex, age, rank, years of education, tenure at the Identification Unit, and tenure at the renewal table. The information on technical failures among the digital tables was also collected from administrative records and it was collected on a daily basis.

\section{Subpopulation of analysis}

The subpopulation of analysis in this study are all individuals who officially applied for an ID card renewal, in the city of La Paz, during the data collection time period. This subpopulation of analysis is not representative of the whole population, but rather of those individuals who decide to apply for an ID card renewal. The sample of applicants used in the subsequent analysis excludes all applicants younger than 21 years old and those older than 100 years old.

\section{Descriptive statistics}

The summary statistics of the data used in the study are presented in Table 2. The statistics are estimated separately by completion status and type of renewal process. The type of renewal process for digital tables does not correspond to the original renewal process, but rather to an ex-post measure already adjusted for technical failures. Panel A presents the ex-post average values for the outcome variables considered in the paper, which are measured at the police officer-applicant pair level. Panels B and C report the basic characteristics of applicants and police officers. These are ex-ante characteristics measured at the randomization table. Panel D summarizes technical failures measured at the renewal day-table level. The aim of this summary table is twofold. First is to verify that police officers and applicants characteristics are well balanced across type of renewal process. Second, is to explore whether ex-post successful and unsuccessful applicants might vary systematically along some of these characteristics.

The average age of an applicant for both the digital and manual renewal tables is 40 years old, with roughly 48 percent of them being women in both groups. About 63 percent of applicants in both groups

\footnotetext{
${ }^{7}$ Indigenous women wear their hair in two long braids decorated with tassels, and dress in distinctive skirts over puffy petticoats.
} 
have finished high school, and a low 14 percent of those who ever attended school were enrolled in a private school across the two type of renewal groups. Roughly 16 percent of the applicants assigned to either of the renewal processes are from the rural area. On average, 56 percent of applicants who start the renewal process speak an indigenous language (55.5 percent in the digital tables group and 56.3 percent in the manual tables group), and 30 percent of women wear an indigenous attire (29.6 percent in the digital tables group and 31.1 percent in the manual tables group). The differences in sample means along all these basic characteristics of applicants are not significant at the 5 percent level. ${ }^{8}$

As for public officials, the average tenure at the renewal table is 1 year $(1.18$ for public officials at digital renewal tables and 0.96 for those at manual ones). A typical police officer has been working at the Identification Unit for about 3 years (2.97 for public officials at digital renewal tables and 3.04 for those at manual ones). Further, a typical police officer is 35 years old (33.94 for those digital renewal tables and 37.91 for those at manual ones), and has 13 years of completed school (13.44 for those at digital renewal tables and 12.78 for those at manual ones). About 64 percent of police officers are low rank (61.11 at digital renewal tables and 67.83 at manual ones), and only 24 percent are women (22.2 for those at digital renewal tables and 26.1 for those at manual ones). Although some of the difference in means seem large (police officer age, sex, and rank), none of the differences in means are significant at the 5 percent level. Overall, the statistics reported above suggest a good balance of applicants and police officers across type of renewal process.

The table also shows that only 66 percent of applicants assigned to a manual table get to complete the renewal process. In contrast, almost 82 percent of applicants assigned to a digital table get to complete the renewal process successfully. The difference in sample means across type of renewal process is large and significant at the 5 percent level. For applicants who get to complete the process, a typical renewal process takes roughly 85 minutes in a digital table and 129 minutes in a manual one. The difference in sample means across type of renewal process is again significant at the 5 percent level. Despite the fact that ex-ante characteristics of applicants do not vary substantially across type of renewal process, ex-post the characteristics of applicants vary substantially across completion status. For instance, comparing Column (3) with Column (5), and comparing Column (4) with Column (6), we see that applicants who do not get to complete the renewal process are on average less educated, come from the rural area, are less likely to have attended a private school, and are more likely to be of indigenous descent (either speak an indigenous language or wear indigenous attire). The differences in sample means for all of the applicants' characteristics (except for age) are significant at 5 percent level (both for successful and unsuccessful applicants).

\footnotetext{
${ }^{8}$ Census data for the city of La Paz reports the following average characteristics for the population: 51 percent women, 44 percent completed high school (average years of education is 9.4), 22 years old, 38 percent live in the rural areas, and 68 percent are indigenous.
} 


\section{Discussion of experimental results}

\section{Renewal success rates}

Table 3 presents the effects of information technologies on the probability of successfully completing a renewal process. All the coefficients reported are marginal effects from probit regressions, and are separately estimated for male and female applicants to exploit the indigenous attire data collected for the subsample of female applicants. ${ }^{9}$ The effect of information technologies over traditional technologies after controlling for renewal day fixed effects - that is, the coefficient $\beta$ in Equation 1 - is presented in columns (1) and (3) for male and female applicants, respectively. Columns (2) and (4) present instead the effect of information technologies over traditional technologies after controlling for police officer fixed effects - that is, the coefficient $\gamma$ in Equation 2. The estimation of these two regression models allows for assessing the extent to which unobserved police officer characteristics might be correlated with the ability to successfully complete a renewal process. Columns (5) to (8) show the results of estimating Equations 3 and 4, which control for the characteristics of the applicants and allow for technologies to interact with these characteristics. Columns (5) and (6) show the estimates for the subsample of male applicants, while those for female applicants are reported in columns (7) and (8). These alternative specifications allow assessing the extent to which applicants's characteristics might be important determinants of success rates across type of renewal process.

The results in Table 3 show that the adoption of information technologies resulted in an overall improvement in the service provided by the Police within the process of renewing an ID card. Male applicants randomly assigned to the digital renewal process have on average between 11.55 to 13.22 percentage points higher probability of completing the process as compared to those randomly assigned to the manual one 11.55 when controlling for renewal day fixed effects and 13.22 when controlling for police officer fixed effects. All of these effects are statistically significant at the 1 percent level. The estimates in columns (3) and (4) corroborate these findings for the subsample of female applicants. Female applicants randomly assigned to the digital renewal process have on average between 10.43 to 13.59 percentage points higher probability of completing the process as compared to those randomly assigned to the manual one - 13.59 when controlling for renewal day fixed effects and 10.43 when controlling for police officer fixed effects. All these effects are also statistically significant at the 1 percent.

The characteristics of applicants should not affect success rates. In practice, however, they might if police officers do not provide a homogeneous service across the population or if applicants are affected by bureaucracy differently based on their characteristics. Next, we explore the possibility that applicants' characteristics might be important determinants of success rates. The results of this exercise are presented in columns (5) to (8) and interestingly present strong evidence that indeed success rates vary systematically across renewal process based on the characteristics of the applicants. Applicants from relatively disadvantaged backgrounds are much less likely to complete the renewal process. On average, applicants from rural areas are 10 percentage points less likely to complete the renewal process as compared to those from the urban area -

\footnotetext{
${ }^{9}$ Table A1-1 in the Appendix reports the results for the pooled sample, and shows that the sex of the applicant is not an important determinant of renewal outcomes.
} 
9.17 to 11.80 percentage points depending on the sex of applicant and specification of the model. Applicants who did not complete high school are roughly 4 percentage points less likely to complete the renewal process as compared to those who did complete high school - 4.28 to 4.91 percentage points depending on the specification. Senior people are 3 percentage points less likely to complete the renewal process as compared to relatively younger applicants - 2.03 to 3.27 percentage points depending on the specification. Moreover, applicants who never attended private school and, thus, belong to a lower social status, are 10 percentage points less likely to complete the renewal process as compared to those who attended a private school -9.93 to 11.37 percentage points depending on the specification. Lastly indigenous male applicants, as measured by the ability to speak an indigenous language, are roughly 7 percentage points less likely to complete the renewal process as compared to non-indigenous male applicants - 7.32 to 7.39 percentage points depending on the specification. Female applicants wearing an indigenous attire are instead 13 percentage points less likely to complete the renewal process as compared to those female applicants who were not wearing an indigenous attire - 13.26 to 13.38 percentage points depending on the specification. All of these correlations are statistically significant at the 1 percent level. Interestingly, speaking an indigenous language does not seem to be relevant to explain success rates among female applicants after the wearing of an indigenous attire has been controlled for. This suggests that visual inspection might be a more important aspect of being indigenous for citizens' lives as opposed to speaking an indigenous language. Further, it suggests that clothing inspection might be a better measure to classify ethnicity among Bolivian women as opposed to language spoken.

A natural next question that arises is whether the adoption of information technologies within the renewal process might have reduced some of these observed gaps in success rates across the characteristics of the applicants. To examine this, we look at whether the impacts of information technologies differ across applicants with different background characteristics. The estimates are reported in columns (5) to (8), and present one of the most important findings of this paper namely that the digital renewal process is able to reduce most of the observed disparities in renewal outcomes across the characteristics of applicants. In particular, the effect of coming from the rural area is smaller in magnitude and opposite in sign to the magnitude of the effect of the interaction of coming from the rural area with being assigned to a digital process (0.1522 to 0.1622 , depending on the specification). These interactions are all significant at the 1 percent level. The magnitude of the effect of having completed high school is similar in magnitude and opposite in sign to the magnitude of the effect of the interaction of having completed high school with being assigned to a digital process (0.0426 to 0.0647 , depending on the specification). All of these interactions are significant at the 5 percent level. The difference in success rates among senior and younger applicants is reduced by roughly 5 percentage points when applicants are randomly assigned to the digital process as compared to the manual one, though this difference is only significant at standard levels for male applicants. In particular, the magnitude of the effect of being a senior applicant is similar in magnitude and opposite in sign to the magnitude of the effect of the interaction of having completed high school with being assigned to a digital process (0.0573 to 0.0574 , depending on the specification). All of these interactions are again significant at the 1 percent level. Moreover, the gap in success rates between indigenous and non-indigenous applicants as measured by the knowledge of an indigenous language, is reduced by around 5 percentage points when applicants are randomly assigned to the digital renewal process as opposed to the manual one. The magnitude of 
the effect of speaking an indigenous language is similar in magnitude and opposite in sign compared to the magnitude of the effect of the interaction of being a rural applicant with being assigned to a digital process (0.0511 to 0.0574 , depending on the specification). All of these interactions are significant at the 1 percent level. Lastly, the difference in success rates between indigenous and non-indigenous females as measured by indigenous attire, is reduced by around 8 percentage points when applicants are randomly assigned to the digital renewal process as compared to the manual one (0.0814 and 0.0839 , depending on the specification, all significant at the 5 percent level).

As a final exercise, we look at whether the characteristics of police officers might in practice affect success rates. Technology and skills are often believed to be complementary (e.g. Van Reenen and Chennells (2002) and Machin, McNally, and Silva (2006)). Yet, given the homogeneity of police officers and the simple skills required to complete the renewal process, the characteristics of police officers are a priori not expected to affect success rates in this setting. Table A1-2, in the Appendix, presents the results of this exercise. As expected given the nature of the police officers' randomization process, background characteristics of police officers are not significantly correlated with success rates. Moreover, the interactions between technologies and police officers' characteristics are small in magnitude and never significant at standard levels. This is reassuring and suggests that the variation in success rates observed in the data is not the result of observed differences in police officer characteristics.

\section{Time it takes to complete renewal}

Table 4 presents the effect of information technologies on the time it takes to complete a renewal process. For the estimation of these coefficients, we focus on the subsample of applicants who were successful at completing the renewal process. All coefficients are again separately estimated for male and female applicants to exploit the data about indigenous attire collected only for the subsample of female applicants. Columns (1) and (2) present the results from the two basic specifications of the model (Equations 1 and 2) for the subsample of male applicants. Columns (3) and (4) present analog estimates for the subsample of female applicants. In columns (5) and (6), we present estimates from the augmented models (Equations 3 and 4) for the subsample

of male applicants. Finally, in columns (7) and (8), we report the results of these two augmented models for the subsample of female applicants.

The results in Table 4 show that information technologies allow for important efficiencies within the renewal process of renewing an ID card, which directly translate into an improvement in the quality of service provided by the Police to applicants. Male applicants randomly assigned to the digital renewal process take on average between 40.01 to 43.64 fewer minutes to complete the renewal process as compared to those randomly assigned to the manual process - 40.01 when controlling for renewal day fixed effects and 43.64 when controlling for police officer fixed effects. All these effects are statistically significant at the 1 percent level. The estimates in columns (3) and (4) corroborate these findings for the subsample of female applicants. Female applicants randomly assigned to the digital renewal process take on average between 39.14 to 43.57 fewer minutes to complete the renewal process as compared to those randomly assigned to the manual process - 43.57 when controlling for renewal day fixed effects and 39.14 when controlling for 
police officer fixed effects. Again, all of these coefficients are significant at the 1 percent level. Looking across all the specifications shown, we conclude that information technologies are reducing the time it takes to renew an ID card by an average of about 40 minutes. Compared with a level of 128 minutes among manual renewal tables, these point estimates imply a reduction in the time it takes to complete the renewal process of about 31 percent compared to the level in manual renewal tables, which is quite substantial. Figure 2 shows these results graphically presenting for each type of renewal process the estimated probability density function, where the function is estimated using an Epanechnikov kernel. The results show that the time it takes to complete a renewal process is lower for the digital renewal process along all of the percentiles in the distribution. The two-sample Kolmogorov-Smirnov statistic testing for equality of both density functions is 0.5817 ( $p$-value $=0.000)$.

The effect of applicants' characteristics on the time it takes to renew an ID card shows a similar pattern to that reported for the probability of completing the renewal process. Applicants from relatively disadvantaged backgrounds take longer to complete the renewal process when randomly assigned to the digital renewal process as compared to the manual one. Applicants from rural areas take on average 17 minutes more to complete the renewal process as compared to those from the urban area (roughly 13 percent more of the mean renewal time among applicants assigned to the manual process). Applicants who did not complete high school take on average 11 minutes more to complete the renewal process as compared to those who did complete high school (roughly 8.5 percent more of the mean renewal time among applicants assigned to the manual process). Senior people take on average 2 minutes more to complete the renewal process as compared to younger applicants, though this is only significant among female applicants (roughly this corresponds to 7 percent of the mean renewal time among applicants assigned to the manual process). Moreover, applicants who attended a public school, and thus belong to lower socioeconomic strata, take approximately 6 minutes more to complete the renewal process as compared to those who attended private school (this roughly corresponds to 5 percent more of the mean renewal time among applicants assigned to the manual process). Finally, indigenous male applicants, as measured by the ability to speak an indigenous language, take on average 3 minutes more to complete the renewal process as compared to those of nonindigenous descent (2 percent more of the mean renewal time among applicants assigned to the manual process). Female applicants wearing an indigenous attire take on average 4 minutes more to complete the renewal process as compared to female applicants not wearing an indigenous attire ( 3 percent more of the mean renewal time among applicants assigned to the manual process). Consistent with previous findings, speaking an indigenous language is not relevant to explain renewal time for renewal among female applicants after wearing of an indigenous attire has been controlled for. All these coefficients are statistically significant at the 5 percent level.

Table 4 also reports the interactions between the information technologies coefficient and the characteristics of the applicants. These estimates present evidence that information technologies do have different effects on time it takes to complete a renewal process based on the characteristics of the applicants. These effects, however, are relatively modest compared to those found for success rates. On average, information technologies reduce the gap between rural and urban applicants by 14 minutes - this is roughly 11 percent of the mean renewal time among applicants assigned to the manual process. Information technologies also 
reduce the gap in success rates among applicants who completed high school and those who did not. The reduction in the gap is around 10 minutes, which roughly corresponds to 8 percent of the mean renewal time among applicants assigned to the manual process. Lastly, the gap in success rates between applicants who never attended private school and those who did is reduced by 4 minutes, which corresponds to 3 percent of the mean renewal time among applicants assigned to the manual process. The magnitude of all of these coefficients is consistent across all specifications of the model and the sex of the applicant. Further, all these interactions are significant at the 5 percent level.

For completeness, Table A1-2, in the Appendix, explores also whether information technologies might affect the time it takes to complete the process by interacting with some of the observed characteristics of police officers. Consistent with the previous findings for success rates, the characteristics of police officers have no power to explain variation in the time it takes to complete a renewal process. Estimates are always small in magnitude and never significant at standard levels.

\section{Are differences in renewal outcomes based on characteristics of applicants fully elimi- nated by the digital process?}

An interesting exercise is checking whether the use of technologies in this setting are able to eliminate the differences in renewal outcomes based on the characteristics of applicants. To do so, we test for whether the different characteristics of applicants and its interaction with the type of renewal process are jointly significant at the 10 percent level. The intuition behind this test is the following. If we fail to reject the null that a specific characteristic of an applicant and its interaction with the digital renewal process is significant, that would indicate that disparities in renewal outcomes along that dimension have been eliminated by the digital process. That is, it would mean that under the digital process it would no longer matter whether the individual is from the rural or urban area, whether he is from an indigenous background or not, and so on and so forth.

The results of these tests of significance are presented in Table 5 . The statistics correspond to the estimates reported in columns (5), (6), (7), and (8) of Tables 3 and 4, which correspond to the full specification of the model estimated separately for the subsample of male and female applicants using the two identification strategies. The reported coefficients are the combined estimates of the null hypotheses reported in the left hand side. The p-values correspond to the $\chi^{2}$ and $F$ statistics for the null hypotheses of the success indicator and duration outcomes, respectively. The statistics suggest that the digital renewal process is successful at eliminating many of the observed differences in success rates among male applicants, including those resulting from the educational level and indigenous background of the applicant. In fact, under the digital renewal process rural male applicants are actually between 3.47 and 4.09 percent more likely to complete the renewal process than male applicants from the urban areas depending on the specification, and senior male applicants are between 1.42 and 2.53 percent more likely to complete the renewal process as compared to younger male applicants. In contrast, male applicants from poorer backgrounds as measured by attendance to a public school are still between 5.02 and 5.52 percent less likely to complete the renewal process as compared to those from relatively better off backgrounds. 
The digital renewal process is also successful at eliminating the differences in success rates among female applicants based on educational level, indigenous attire, and socioeconomic status as measured by whether the female applicant attended public school. Further, under the digital renewal process, rural female applicants are actually between 6.86 and 6.95 percent more likely to complete the renewal process than male applicants from the urban areas, depending on the specification, senior female applicants are between 0.56 and 4.89 percent more likely to complete the renewal process as compared to younger female applicants, and female applicants from indigenous backgrounds as measured by attire are between 4.96 and 5.11 percent more likely to complete the renewal process as compared to those from non-indigenous backgrounds.

Moreover, the digital renewal process is also successful at eliminating most of the observed differences in time it takes to successfully complete a renewal process based on the characteristics of applicants. All differences observed among male applicants in the manual process based on their characteristics are eliminated within the digital process, except for those based on the rural status of the applicant and the socioeconomic status as measured by whether the male applicant attended public school. Yet, under the digital renewal process, rural male applicants still take between 3.07 and 3.15 more minutes to complete the renewal process as compared to male applicants from urban areas, depending on the specification, and male applicants from poorer backgrounds as measured by attendance to a public school take on average 1.44 more minutes to complete the renewal process as compared to those from relatively better off backgrounds. In contrast, all differences observed among female applicants in the manual process based on their characteristics are eliminated within the digital process, except for those based on the indigenous attire and socioeconomic status as measured by whether the female applicant attended a public school. Under the digital process, female applicants from relatively poorer backgrounds as measured by attendance to a public school still take on average 1.94 more minutes to complete the renewal process as compared to those from relatively better off backgrounds, and female applicants from indigenous backgrounds as measured by attire take on average 3.16 more minutes to complete the renewal process as compared to those from non-indigenous backgrounds.

\section{Interpretation}

A natural question that arises is why information technologies might be affecting renewal outcomes and, even more interesting, why in this setting they are so effective at lowering barriers in access to ID cards by citizens. To the extent that we only look at renewals in this study, differential paperwork quality among applicants required to complete the process is not a possible explanation for the variation in renewal outcomes observed in the data. More specifically, individuals applying for an ID card renewal are applicants who five years ago (i.e. the renewal time frame) were able to successfully obtain an ID card. This implicitly means that the Identification Unit should already have all the paperwork required to complete the renewal process for each of those applicants. Moreover, if selection bias based on paperwork quality might be an issue here, we would expect to observe exactly the opposite. Given that rural applicants face higher time and money costs to access the Identification Unit, rural applicants should in general have higher quality paperwork conditional on getting to the Unit. 
Information technologies in this setting clearly introduce efficiencies within the renewal process, including accessing the vital records of the applicants online and reducing administrative shortcomings such as deficient record keeping, typing mistakes, etc. Further, information technologies significantly facilitate the process for applicants by allowing them to perform all of the renewal process steps within one physical location. Yet, the differential effects of these technologies across the characteristics of applicants, and the fact that the characteristics of applicants are important determinants of variation in renewal outcomes, is not fully consistent with a simple story of efficiencies within this process. In particular, the fact that the characteristics of applicants are important predictors of variation in renewal outcomes is consistent with four hypotheses. First, police officers might not be providing a homogeneous service across the population, wherein police officers provide different service quality to applicants based on their intrinsic characteristics. The provision of different service quality to applicants in detriment of applicants of relatively disadvantaged backgrounds has been previously reported as an important barrier in access to ID cards by citizens in Bolivia (e.g. World Bank (2000), Mansilla (2003), Quintana (2003), and Wanderley (2007)). My results are consistent with all of this previous evidence based on qualitative data. Further, to the extent that information technologies reduce the possibility of exercising discretion as far as missing vital records across applicants, this hypothesis is also consistent with the observed reduction in success rates gaps across applicants resulting from the use of these technologies. Yet, if differential service quality provision to applicants based on their characteristics were the only mechanism operating to lower barriers in access to ID cards in this setting, we would not expect to observe changes in the time it takes to complete a renewal resulting from the adoption of these technologies. In particular, information technologies do not introduce any particular incentive for police officers to change their service provision patterns based on the type of renewal. To this end, it is plausible that something else, in addition to differential service quality provision to applicants based on their characteristics, might be operating here that is forcing police officers to discriminate less frequently against relatively disadvantaged applicants when randomly assigned to the digital process.

A second hypothesis that is consistent with the fact that applicants' characteristics are important determinants of access to ID cards is that police officers might be practicing selective enforcement of rules. Selective enforcement of rules is possible, in this setting, because of the opportunities that police officers have to exercise discretion at completing some of the renewal steps. The intuition behind the selective enforcement of rules is as follows. To maximize the possibility of extracting bribes from applicants, police officers would purposely complicate the process to create incentives for applicants to incur in extra-legal payments and finish with the process. Applicants at higher risk of being targeted are those from relatively disadvantaged backgrounds, which tend to be less demanding and likely to voice complaints. These results would be consistent with previous literature on petty corruption within public service delivery in several developing countries, and would also be consistent with the possibility that information technologies might act as a brake to curb petty corruption within this specific bureaucratic process. ${ }^{10}$ Moreover, the existence of

\footnotetext{
${ }^{10}$ The literature on corruption within public service delivery has looked mainly at how bureaucrats price discriminate when setting bribes and the social and economic costs of corruption. Svensson (2003) and Fisman and Svensson (2007) find evidence that corrupt bureaucrats act as price discriminators in determining access to public services. Olken and Barron (2009) collect field data on bribe payments by truckers to road post officials, in Indonesia, and find evidence that corrupt bureaucrats behave like price discriminating profit-maximizing firms. Bertrand, Djankov, Hanna, and Mullainathan (2007) provide experimental evidence that bureaucrats undercut existing regulations on obtaining a driving
} 
petty corruption within the the Bolivian Police has already been documented (United Nations Development Program, 2006). In an interesting nationally representative survey about the bureaucratic services provided by the Police, only 28 percents of citizens agreed that it was possible to successfully complete a bureaucratic process involving the Police without having to incur an extra-legal payment, 47 percent of citizens admitted to have paid at least an extra-legal payment in the last year in order to facilitate the completion of a bureaucratic process, and 30 percent of citizens reported explicitly being asked for a bribe by a police officer in order to complete a process. By eliminating the possibility that police officers might lie about not finding the vital records of an applicant, information technologies implicitly add an accountability mechanism into the renewal process. This accountability mechanism might be successfully operating in this setting to reduce barriers in access to ID cards by explicitly altering the probability of detecting malpractices among police officers.

The third hypothesis consistent with the fact that applicants characteristics are important determinants of renewal outcomes is that excessive bureaucracy or red tape affects applicants differently based on their characteristics. For instance, illiterate applicants might find it harder to navigate the renewal process steps than those applicants with some schooling because they are not able to read the signs at the Unit. This would be further exacerbated by the fact that police officers seem to be quite efficient at identifying relatively disadvantaged applicants so as to search for opportunities to extract bribes. Excess bureaucracy might be intimidating to many people, particularly so to groups socially excluded from the mainstream. It is usually believed that people from relatively disadvantaged backgrounds are less able to access and process information, in part because they have relatively limited education. Endogenous red tape might be introducing an important inequality dimension into the renewal process by requiring some skills from applicants to successfully complete the process. To the extent that these skills are not necessarily uniformly distributed across applicants, this would directly translate into differential renewal outcomes based on the characteristics of the applicants. By allowing applicants to perform all the renewal steps within one physical location, information technologies might be significantly facilitating the process for the applicant and, thus, reducing observed gaps in renewal outcomes based on the characteristics of applicants.

Lastly, bureaucratic delay might affect applicants based on their time preferences and, thereinafter, affect the success rates based on their intrinsic characteristics. For instance, applicants who find bureaucratic delay overwhelming might decide to drop out at some point in the middle of the renewal process and come back at some other point in time to the Identification Unit to start a new renewal process (renewal processes cannot be put on hold - if they are not completed by the end of the day, the applicant needs to start a whole new renewal process). Because of the nature of my data collection, drop-outs are implicitly classified as unsuccessful applicants in my sample. Yet, it is highly unlikely that these represent a large proportion of unsuccessful applicants. In particular, applicants deciding to drop-out in the middle of the renewal process face transportation expenses and substantial time costs. Because of the marking ink used to mark applicants' thumbnails at the randomization table, applicants cannot start a new renewal process right away but need to wait for at least a couple of days until the marking ink has faded away. Further, deciding to drop-out

license, in India, responding to the needs of private agents. Sequeira and Djankov (2008) find empirical evidence that bureaucrats working in ports within Southern Africa price-discriminate according to characteristics of the shipments and products when setting bribes. 
in the middle of the renewal process is very costly for the applicant to the extent that queuing time at the randomization table can easily take between 40 to 60 minutes. Therefore, drop-outs should be minimal in my sample and occur only randomly across the population of applicants. In addition, there is a piece of evidence against the possibility that drop-outs might be occurring systematically in my sample. Applicants from relatively stronger backgrounds are, in general, expected to have a higher opportunity costs of their time (e.g. Frey (1971), Shaw (1992)). If differences in time preferences might be driving my results, we would expect to observe that applicants from relatively better-off backgrounds tend to be more unsuccessful, perhaps dropping-out to look for an unofficial way to get their ID cards. However, we observe the opposite in my sample. Applicants from relatively disadvantaged backgrounds tend to be more unsuccessful. Therefore, my results present little evidence to support the hypothesis that bureaucratic delay might be affecting applicants renewal outcomes based on their intrinsic time preferences.

\section{Concluding remarks}

Public service delivery in developing countries is rife with red tape, corruption, and bureaucratic delay. As information technologies continue to rapidly evolve, policy makers and regulators in developing countries are increasingly adopting them as a tool to enhance government efficiency, public administration, and transparency. This paper builds on the empirical micro literature about the effects of information technologies on public service delivery, and provides evidence that it might be possible to dramatically improve the quality of public service delivery by the adoption of simple information technologies. Further, it shows evidence that under the right set of conditions, information technologies might prove effective tools at lowering barriers in access to public services.

We investigate the potential of information technologies to improve public service delivery in the context of two unusual randomized natural experiments occurring within one particular bureaucratic process: the renewal of a national identification card by the Bolivian Police. The results of this paper show that the introduction of information technologies into this bureaucratic process led to significant improvements in the quality of service provided to citizens. Applicants assigned to the digital renewal process are on average 12 percentage points more likely to complete the renewal process as compared to those assigned to the traditional old manual process. Further, applicants assigned to the digital renewal process who are able to complete the process take, on average, 31 percent less time to complete the process as compared to those assigned to the manual one. In this setting, information technologies seem to be translating into an improvement in overall efficiency within this bureaucratic process by allowing for efficiencies within the renewal process, including accessing the vital records of the applicants online, and reducing administrative shortcomings such as deficient recording, typing mistakes, etc.

Moreover, my results present strong evidence that the use of information technologies within this bureaucratic process is an effective tool at lowering barriers in access to national identification cards by citizens and, thus, an effective tool at promoting equitable public service delivery. Information technologies, in this setting, seem to be translating into an a more homogeneous quality of service across applicants by reducing 
transaction costs (allowing applicants to perform all of the renewal process steps within one physical location) and improving accountability (eliminating the possibility that police officers might lie about not finding the vital records of an applicant as now they can access vital records online that allow applicants to directly monitor this process). ${ }^{11}$ we discuss several mechanisms through which information technologies might be promoting equitable public service delivery within this bureaucratic process. Overall, my findings are consistent with the existence of differential service quality provision to applicants based on their characteristics and selective enforcement of rules by police officers, and the possibility that red tape might affect applicants differently based on their intrinsic characteristics.

Given the significant low quality of public service delivery in developing countries, and the relatively low cost of adopting these technologies, the results presented in this paper are encouraging. Despite that the role of technologies will clearly vary from place to place and from service to service, the results of this paper present strong evidence that information technologies have the potential to transform the way in which governments interact with citizens and the manner in which services are delivered to the public. This paper provides some insights into attempts at public service reform in developing countries and suggests that, under a right set of circumstances and government implementation capacity, information technologies can serve as an effective tool to advance development objectives.

\footnotetext{
${ }^{11}$ Under the manual renewal process, the vital records of the applicants are accessed directly from a Vital Records Archive maintained at the basement of the building which is only accessible to police officers
} 


\section{References}

Bertrand, M., S. Djankov, R. Hanna, and S. Mullainathan (2007): "Obtaining a Driver's License in India: An Experimental Approach to Studying Corruption," The Quarterly Journal of Economics, 122(4), 1639-1676.

Bresnahan, T., and R. Gordon (1997): The Economics of New Goods (National Bureau of Economic Research Studies in Income and Wealth), vol. 58. University of Chicago Press.

Colecchia, A., And P. Schreyer (2001): "ICT Investment and Economic Growth in the 1990s: Is the United States a Unique Case? A Comparative Study of Nine OECD Countries," Oecd science, technology and industry working papers, OECD, Directorate for Science, Technology and Industry.

Draca, M., R. Sadun, and J. V. Reenen (2006): "Productivity and ICT: A Review of the Evidence," CEP Discussion Papers dp0749, Centre for Economic Performance, LSE.

Duryea, S., A. Olgiati, and L. Stone (2006): "The Under-Registration of Births in Latin America," RES Working Papers 4443, Inter-American Development Bank, Research Department.

Fisman, R., And J. Svensson (2007): "Are corruption and taxation really harmful to growth? Firm level evidence," Journal of Development Economics, 83(1), 63-75.

Frey, B. S. (1971): "Why do High Income People Participate More in Politics?," Public Choice, 11, pp. 101-105.

Griliches, Z. (1998): "Productivity, R\&D, and the Data Constraint," in REDD and Productivity: The Econometric Evidence, NBER Chapters, pp. 347-374. National Bureau of Economic Research, Inc.

Inter-American Development Bank (2011): "Development Connections," Flagship publication, Washington DC.

Machin, S., S. McNally, and O. Silva (2006): "New Technology in Schools: Is There a Payoff?," CEE Discussion Papers 0055, Centre for the Economics of Education, LSE.

Mansilla, H. C. F. (2003): La Policía Boliviana: Entre los códigos informales y los intentos de modernización. Plural Editores, La Paz-Bolivia.

Olken, B. A., And P. Barron (2009): "The Simple Economics of Extortion: Evidence from Trucking in Aceh," Journal of Political Economy, 117(3), 417-452.

Quintana, J. R. (2003): Policía y Democracia en Bolivia: Una política institucional pendiente. Programa de Investigación Estratégica en Bolivia, La Paz-Bolivia.

Schreyer, P. (2000): "The Contribution of Information and Communication Technology to Output Growth: A Study of the G7 Countries," OECD Science, Technology and Industry Working Papers 2000/2, OECD, Directorate for Science, Technology and Industry. 
Sequeira, S., and S. Djankov (2008): "On the Waterfront: An Empirical Study of Corruption in Ports," Mimeograph, Harvard University.

Shaw, W. D. (1992): "Searching for the Opportunity Cost of an Individual's Time," Land Economics, 68(1), 107-115.

Stiroh, K. J. (2001): "Information Technology and the U.S. Productivity Revival: What Do the Industry Data Say?," Staff Reports 115, Federal Reserve Bank of New York.

Sunden, S., and G. Wicander (2006): Information and communication technology applied for developing countries in a rural context. Faculty of Economic Sciences, Communication and IT, Information Systems, Karlstad University.

Svensson, J. (2003): "Who Must Pay Bribes And How Much? Evidence From A Cross Section Of Firms," The Quarterly Journal of Economics, 118(1), 207-230.

UDAPE (2009): "Dossier de Estadísticas, Unidad de Análisis de Políticas Sociales y Económicas, vol 19," La Paz, Bolivia.

United Nations Development Program, (2006): "Policía Nacional y seguridad ciudadana," Programa de las Naciones Unidas para el Desarrollo, La Paz-Bolivia.

Van Reenen, J., And L. Chennells (2002): "The effects of technical change on skills, wages and employment: A survey of the micro-econometric evidence," in Productivity, inequality, and the digital economy: A transatlantic perspective, ed. by N. Greenan, Y. L'Horty, and J. Mairesse. MIT Press, Cambridge, Mass.

Wanderley, F. (2007): Ejercer Ciudadanía En Bolivia: Sociología Del Estado. Informe de Desarrollo Humano (IDH) - PNUD.

World Bank (2000): "From Patronage to a Professional State: Bolivia Institutional and Governance Review," .

World Bank (2011): "Capturing Technology for Development: An Evaluation of World Bank Group Activities in Information and Communication Technologies," The Independent Evaluation Group, Washington DC. 


\section{Chapter 1 Figures and Tables}

Figure 1: Software platform used for the data collection at the Identification Unit, La Paz, Bolivia, 2009

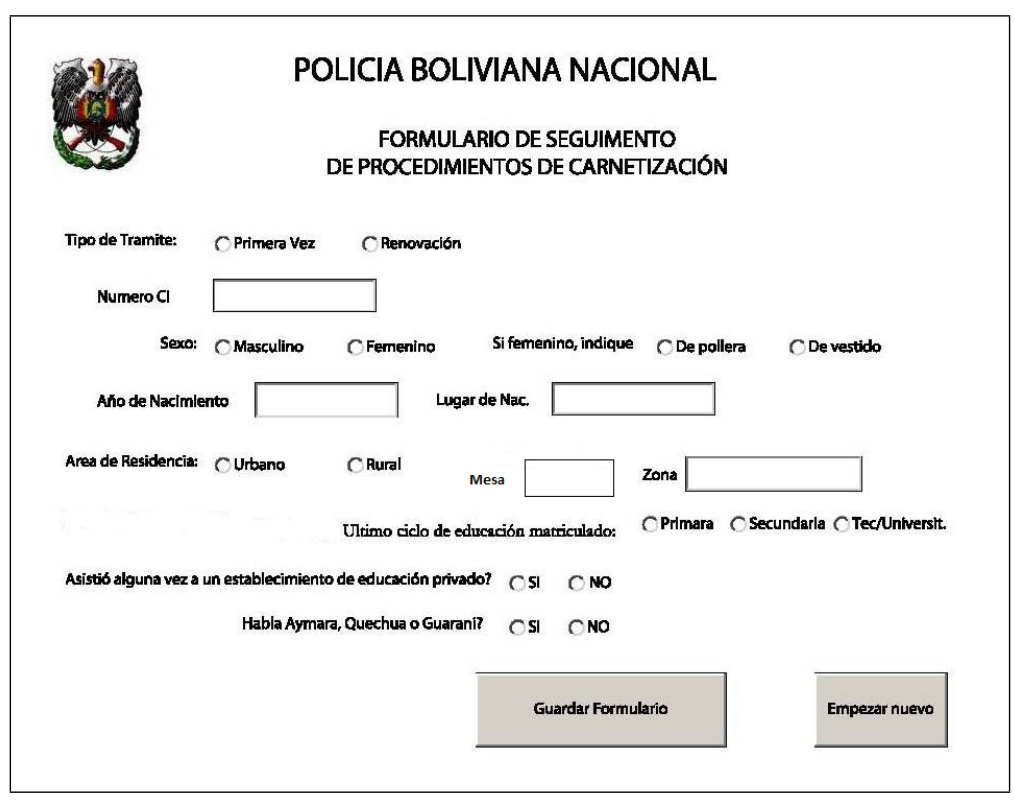

Figure 2: Empirical distribution of the time it takes to complete a renewal, La Paz, Bolivia, 2009

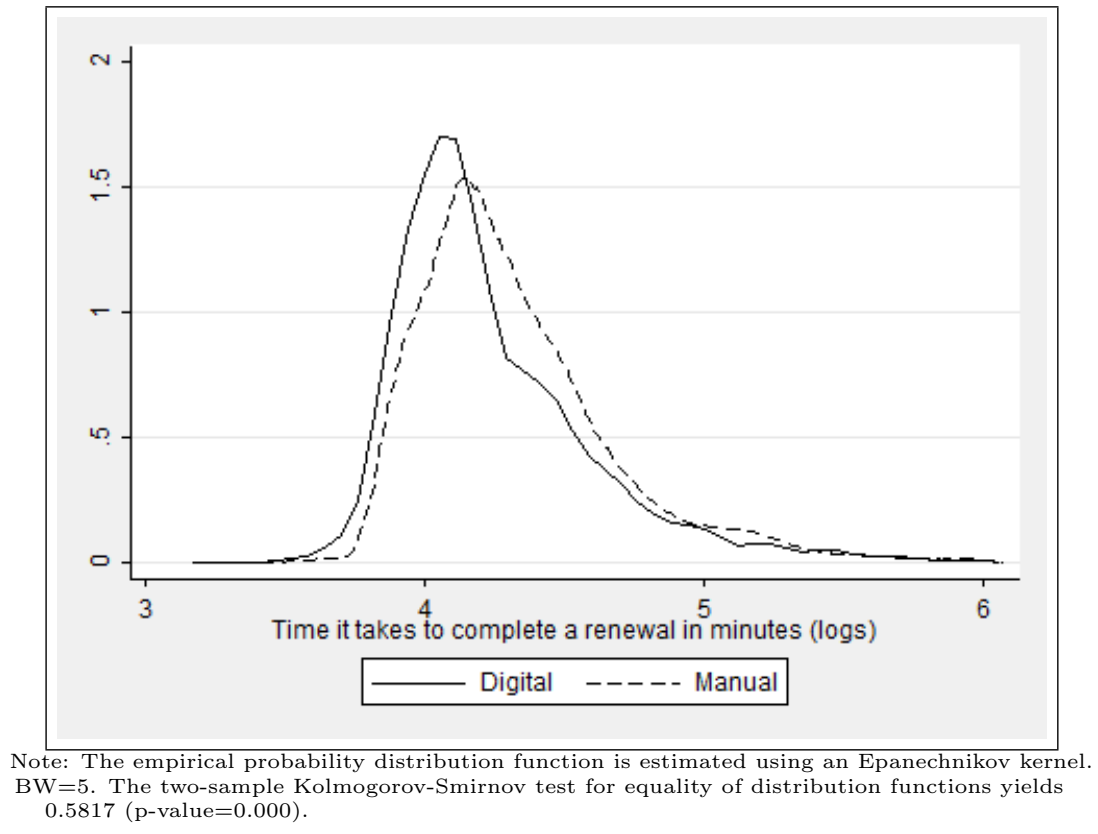


Table 1: Relationship between the probability of being assigned to the digital renewal process, police officers, and applicant characteristics, La Paz, Bolivia, $2009^{a}$

\begin{tabular}{|c|c|c|c|c|c|}
\hline & $\begin{array}{l}\text { Digital } \\
\text { process }\end{array}$ & $\begin{array}{c}\text { Digital } \\
\text { process }\end{array}$ & $\begin{array}{l}\text { Digital } \\
\text { process }\end{array}$ & $\begin{array}{l}\text { Digital } \\
\text { process }\end{array}$ & $\begin{array}{l}\text { Digital } \\
\text { process }\end{array}$ \\
\hline & $(1)$ & $(2)$ & $(3)$ & $(4)$ & $(5)$ \\
\hline & $\begin{array}{l}\text { All police } \\
\text { officers }\end{array}$ & $\begin{array}{r}\mathrm{M} \\
\text { appl }\end{array}$ & $\begin{array}{l}\text { le } \\
\text { cants }\end{array}$ & $\begin{array}{r}\text { Fen } \\
\text { appli }\end{array}$ & $\begin{array}{l}\text { ale } \\
\text { ants }\end{array}$ \\
\hline Police officer has low tenure at renewal table & $\begin{array}{c}-0.0647^{* *} \\
(0.035)\end{array}$ & & & & \\
\hline Police officer is low rank & $\begin{array}{c}0.0481^{*} \\
(0.032)\end{array}$ & & & & \\
\hline Police officer did not go to college & $\begin{array}{c}-0.0211 \\
(0.173)\end{array}$ & & & & \\
\hline Police officer is a senior ( $>35$ years old) & $\begin{array}{c}-0.1826 \\
(0.167)\end{array}$ & & & & \\
\hline Police officer is female & $\begin{array}{c}-0.0145 \\
(0.187)\end{array}$ & & & & \\
\hline Applicant is from the rural area & & $\begin{array}{c}-0.0394^{*} \\
(0.023)\end{array}$ & $\begin{array}{c}-0.0405^{*} \\
(0.023)\end{array}$ & $\begin{array}{c}-0.0072 \\
(0.016)\end{array}$ & $\begin{array}{c}-0.0052 \\
(0.016)\end{array}$ \\
\hline Applicant did not finish high school & & $\begin{array}{l}0.0191 \\
(0.021)\end{array}$ & $\begin{array}{l}0.0196 \\
(0.021)\end{array}$ & $\begin{array}{c}-0.0298^{*} \\
(0.016)\end{array}$ & $\begin{array}{r}-0.0288^{*} \\
(0.016)\end{array}$ \\
\hline Applicant speaks an indigenous language & & $\begin{array}{l}0.0045 \\
(0.009)\end{array}$ & $\begin{array}{l}0.0031 \\
(0.010)\end{array}$ & $\begin{array}{l}0.0026 \\
(0.016)\end{array}$ & $\begin{array}{l}0.0035 \\
(0.016)\end{array}$ \\
\hline Applicant is a senior ( $>40$ years old) & & $\begin{array}{c}-0.0168 \\
(0.012)\end{array}$ & $\begin{array}{c}-0.0158 \\
(0.012)\end{array}$ & $\begin{array}{c}-0.0063 \\
(0.013)\end{array}$ & $\begin{array}{c}-0.0056 \\
(0.012)\end{array}$ \\
\hline Applicant attended a public school & & $\begin{array}{c}-0.0023 \\
(0.014)\end{array}$ & $\begin{array}{c}-0.0022 \\
(0.014)\end{array}$ & $\begin{array}{c}-0.0137 \\
(0.020)\end{array}$ & $\begin{array}{c}-0.0148 \\
(0.019)\end{array}$ \\
\hline Female applicant wearing indigenous attire & & & & $\begin{array}{l}0.0121 \\
(0.016)\end{array}$ & $\begin{array}{r}0.0096 \\
(0.016)\end{array}$ \\
\hline Renewal day fixed effects & No & No & Yes & No & Yes \\
\hline Renewal table fixed effects & No & No & No & No & No \\
\hline Observations & 41 & 10,029 & 10,029 & 9,513 & 9,513 \\
\hline$p$-value of all listed variables & 0.17 & 0.12 & 0.18 & 0.11 & 0.10 \\
\hline
\end{tabular}


Table 2: Summary statistics of renewal outcomes, applicants' characteristics, police officer characteristics, and technical failures, Bolivia, 2009 ${ }^{a}$

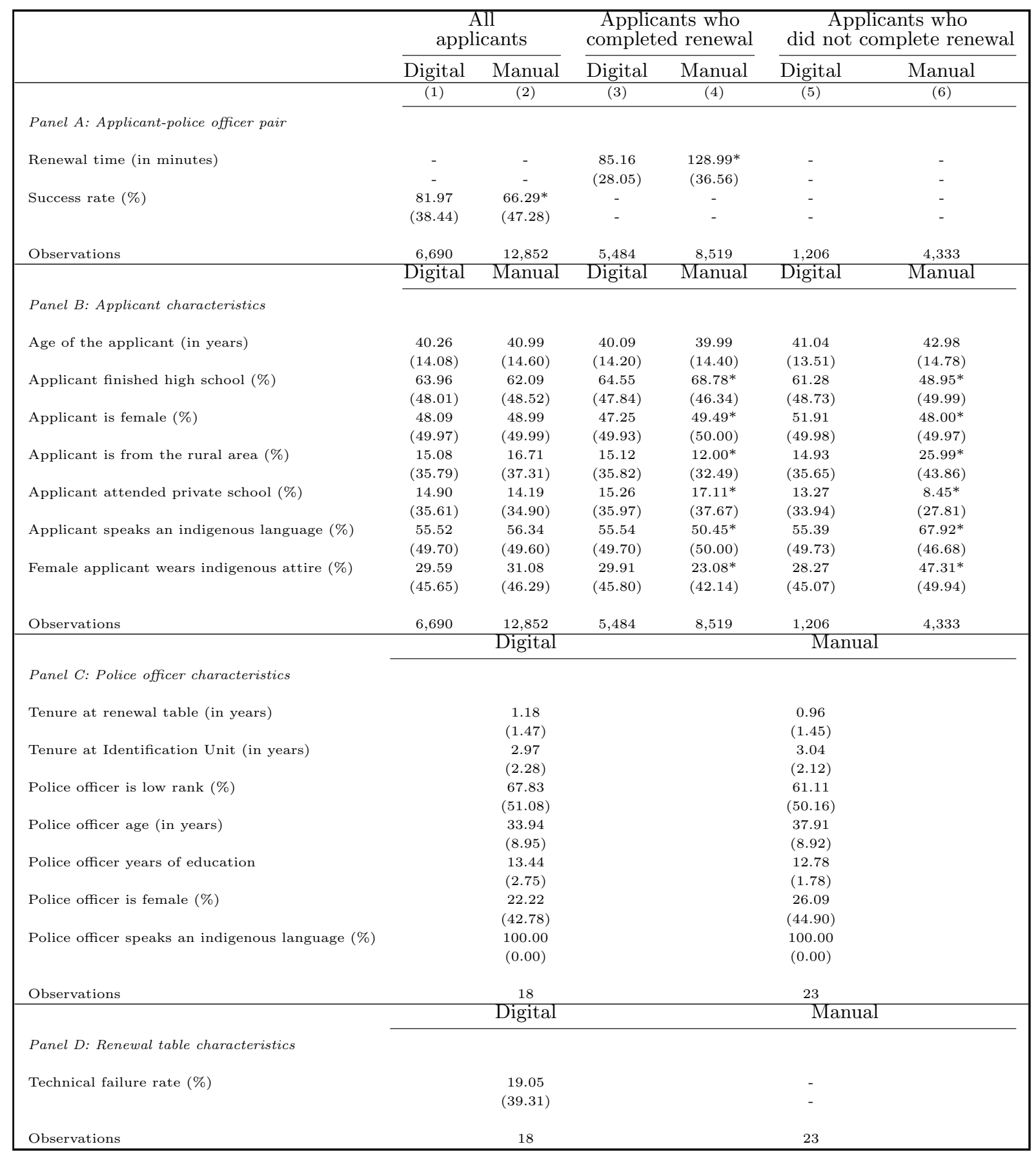

${ }^{a}$ Standard deviations in parentheses. Asterisks in columns (2), (4), (6), and (8) correspond to p $<0.05$ of the difference in means across type of renewal process. 


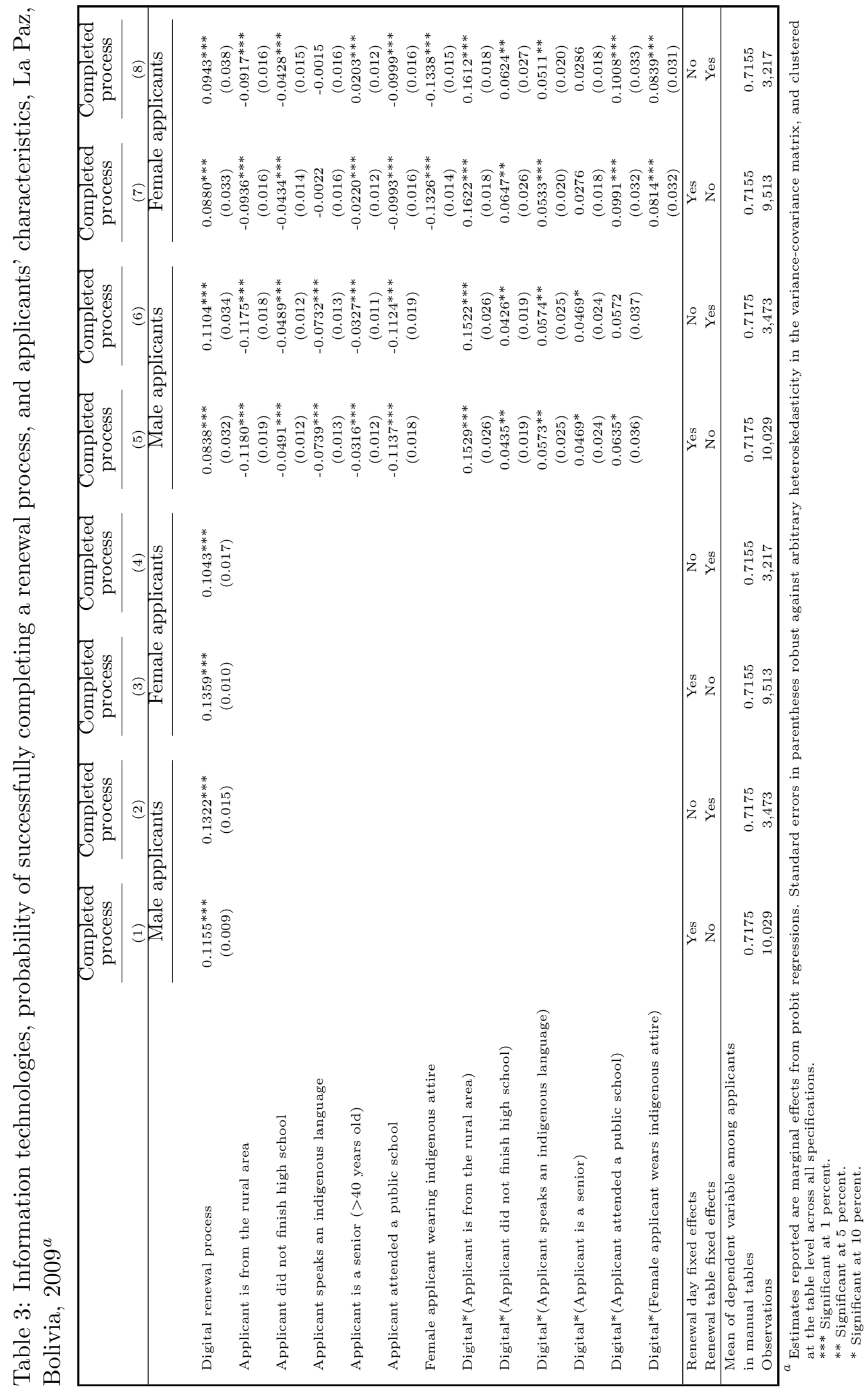




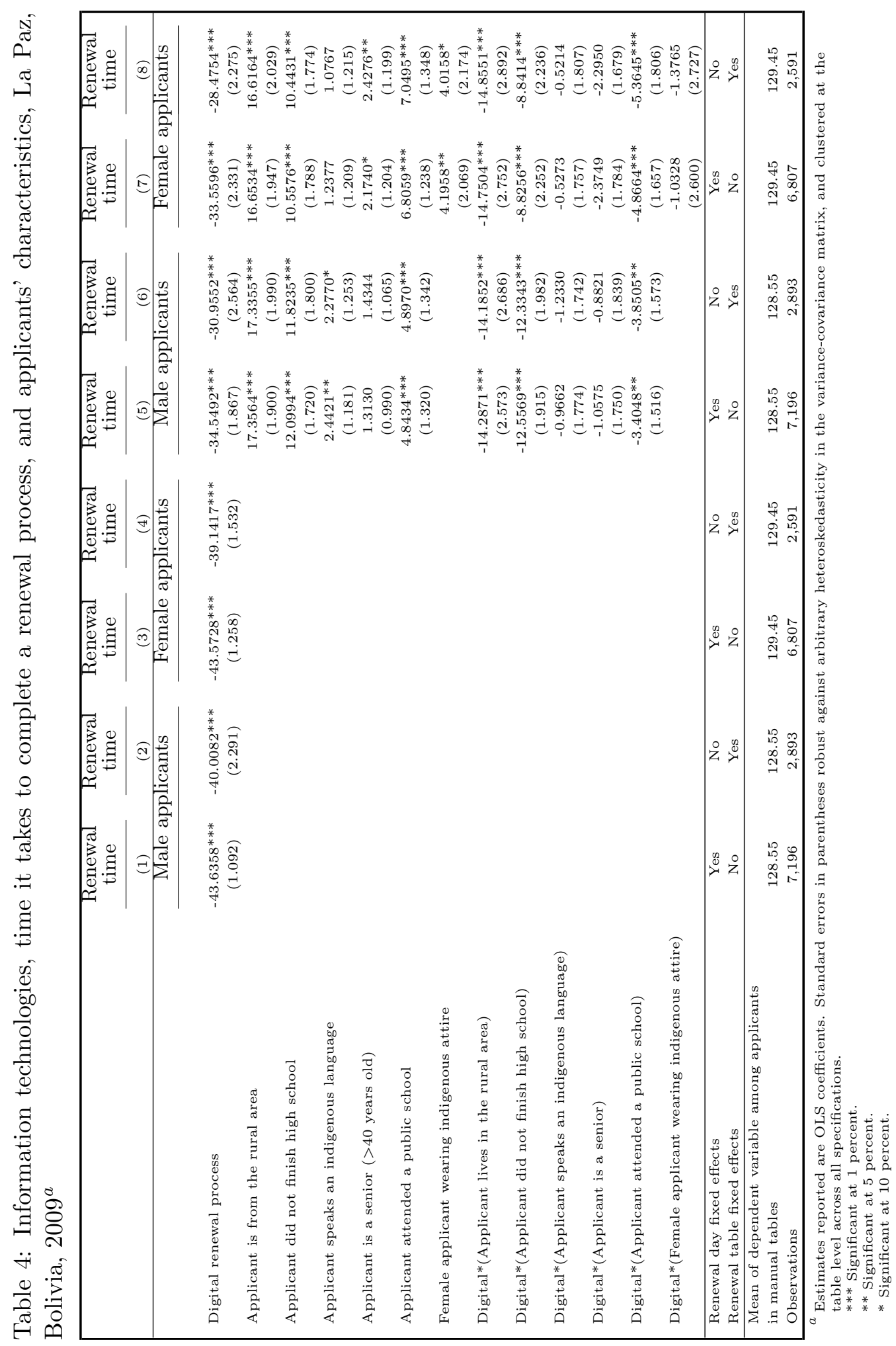




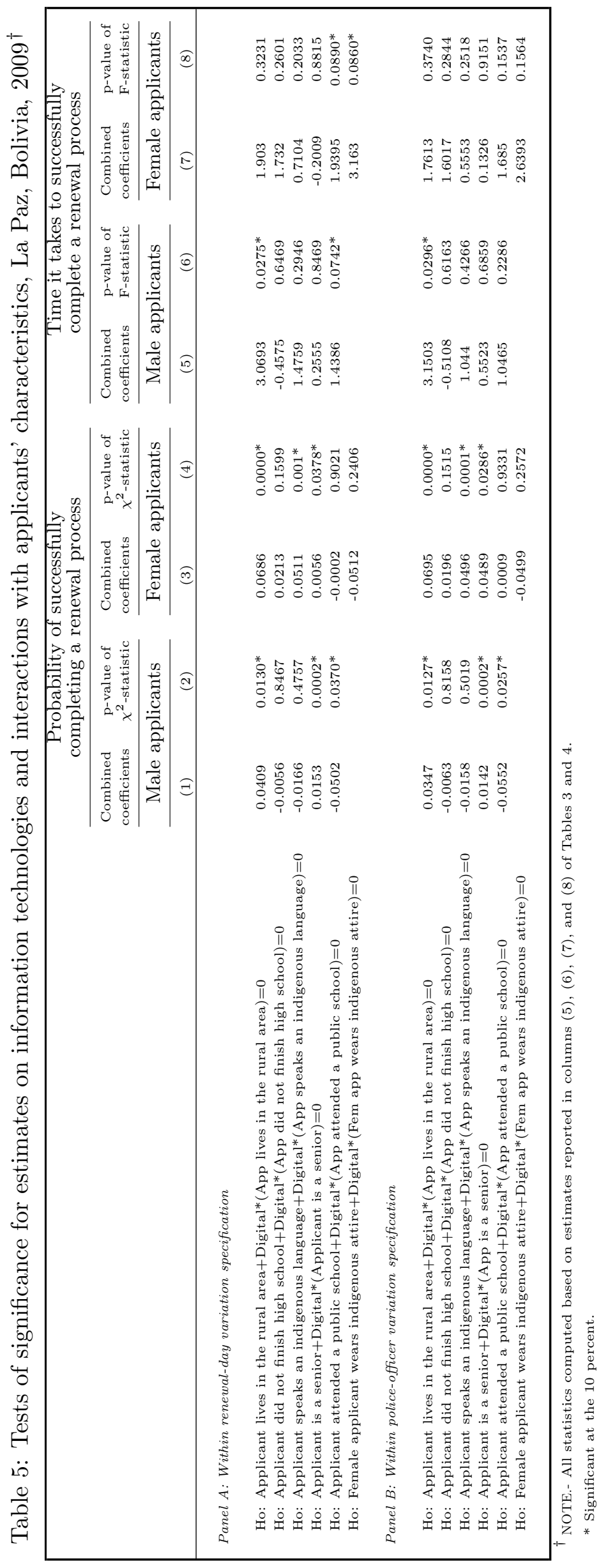


Table A1-1: Information technologies, applicant characteristics, and renewal outcomes: Pooled sample, La Paz, Bolivia, 2009 ${ }^{a}$

\begin{tabular}{|c|c|c|c|c|}
\hline & $\begin{array}{c}\text { Completed } \\
\text { time }\end{array}$ & $\begin{array}{c}\text { Completed } \\
\text { time }\end{array}$ & $\begin{array}{l}\text { Renewal } \\
\text { time }\end{array}$ & $\begin{array}{c}\text { Renewal } \\
\text { time }\end{array}$ \\
\hline & (1) & $(2)$ & (3) & (4) \\
\hline Digital renewal process & $\begin{array}{c}0.0854^{* * *} \\
(0.033)\end{array}$ & $\begin{array}{c}0.1044^{* * *} \\
(0.035)\end{array}$ & $\begin{array}{c}-34.4385^{* * *} \\
(1.695)\end{array}$ & $\begin{array}{c}-30.2110^{* * *} \\
(1.888)\end{array}$ \\
\hline Applicant is a woman & $\begin{array}{c}0.0169^{*} \\
(0.009)\end{array}$ & $\begin{array}{c}0.0167^{*} \\
(0.009)\end{array}$ & $\begin{array}{l}0.3232 \\
(0.792)\end{array}$ & $\begin{array}{l}0.3556 \\
(0.807)\end{array}$ \\
\hline Applicant is from the rural area & $\begin{array}{c}-0.1205^{* * *} \\
(0.011)\end{array}$ & $\begin{array}{c}-0.1208^{* * *} \\
(0.011)\end{array}$ & $\begin{array}{c}17.5266^{* * *} \\
(1.379)\end{array}$ & $\begin{array}{c}17.4644^{* * *} \\
(1.401)\end{array}$ \\
\hline Applicant did not finish high school & $\begin{array}{c}-0.0931^{* * *} \\
(0.008)\end{array}$ & $\begin{array}{c}-0.0926^{* * *} \\
(0.008)\end{array}$ & $\begin{array}{c}11.7325^{* * *} \\
(1.480)\end{array}$ & $\begin{array}{c}11.6634^{* * *} \\
(1.519)\end{array}$ \\
\hline Applicant speaks an indigenous language & $\begin{array}{c}-0.0648^{* * *} \\
(0.008)\end{array}$ & $\begin{array}{c}-0.0646^{* * *} \\
(0.009)\end{array}$ & $\begin{array}{l}1.2326 \\
(0.896)\end{array}$ & $\begin{array}{l}1.1600 \\
(0.930)\end{array}$ \\
\hline Applicant is s senior ( $>40$ years old) & $\begin{array}{c}-0.0210^{* * *} \\
(0.008)\end{array}$ & $\begin{array}{c}-0.0204^{* *} \\
(0.008)\end{array}$ & $\begin{array}{c}1.9634^{* *} \\
(0.834)\end{array}$ & $\begin{array}{c}2.2259^{* *} \\
(0.852)\end{array}$ \\
\hline Applicant attended a public school & $\begin{array}{c}-0.1030^{* * *} \\
(0.012)\end{array}$ & $\begin{array}{c}-0.1026^{* * *} \\
(0.012)\end{array}$ & $\begin{array}{c}5.7138^{* * *} \\
(0.870)\end{array}$ & $\begin{array}{c}5.7979 * * * \\
(0.866)\end{array}$ \\
\hline Digital*(Applicant is woman) $^{*}$ & $\begin{array}{c}0.0509^{* * *} \\
\quad(0.016)\end{array}$ & $\begin{array}{c}0.0508^{* * *} \\
(0.016)\end{array}$ & $\begin{array}{c}-0.5912 \\
(1.030)\end{array}$ & $\begin{array}{c}-0.6777 \\
(1.048)\end{array}$ \\
\hline Digital*(Applicant is from the rural area) & $\begin{array}{c}0.1128^{* * *} \\
(0.013)\end{array}$ & $\begin{array}{c}0.1127^{* * *} \\
\quad(0.013)\end{array}$ & $\begin{array}{c}-14.7005^{* * *} \\
(1.844)\end{array}$ & $\begin{array}{c}-14.7137^{* * *} \\
(1.881)\end{array}$ \\
\hline 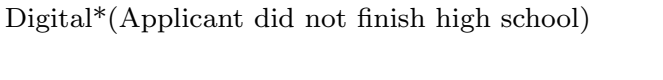 & $\begin{array}{c}0.0662^{* * *} \\
(0.015)\end{array}$ & $\begin{array}{c}0.0655^{* * *} \\
(0.015)\end{array}$ & $\begin{array}{c}-10.7895^{* * *} \\
(1.633)\end{array}$ & $\begin{array}{c}-10.8966^{* * *} \\
(1.679)\end{array}$ \\
\hline Digital*(Applicant speaks an indigenous language) & $\begin{array}{l}0.0731^{* * *} \\
\quad(0.011)\end{array}$ & $\begin{array}{l}0.0733^{* * *} \\
\quad(0.011)\end{array}$ & $\begin{array}{c}-0.7500 \\
(1.378)\end{array}$ & $\begin{array}{c}-0.8998 \\
(1.363)\end{array}$ \\
\hline Digital*(Applicant is a senior) & $\begin{array}{c}-0.0059 \\
(0.017)\end{array}$ & $\begin{array}{c}-0.0062 \\
(0.017)\end{array}$ & $\begin{array}{c}-1.7370 \\
(1.279)\end{array}$ & $\begin{array}{c}-1.7900 \\
(1.296)\end{array}$ \\
\hline Digital*(Applicant attended a public school) & $\begin{array}{c}0.0806^{* * *} \\
(0.025)\end{array}$ & $\begin{array}{c}0.0800 * * * \\
(0.025)\end{array}$ & $\begin{array}{c}-4.0229 * * * \\
(1.150) \\
\end{array}$ & $\begin{array}{c}-4.3694^{* * *} \\
(1.165) \\
\end{array}$ \\
\hline $\begin{array}{l}\text { Renewal day fixed effects } \\
\text { Renewal table fixed effects }\end{array}$ & $\begin{array}{l}\text { Yes } \\
\text { No }\end{array}$ & $\begin{array}{l}\text { No } \\
\text { Yes }\end{array}$ & $\begin{array}{l}\text { Yes } \\
\text { No }\end{array}$ & $\begin{array}{l}\text { No } \\
\text { Yes }\end{array}$ \\
\hline $\begin{array}{l}\text { Mean of dependent variable among applicants } \\
\text { in manual tables } \\
\text { Observations }\end{array}$ & $\begin{array}{l}0.6629 \\
19.542\end{array}$ & $\begin{array}{l}0.6629 \\
19.542\end{array}$ & $\begin{array}{l}128.99 \\
14.003\end{array}$ & $\begin{array}{l}128.99 \\
14.003\end{array}$ \\
\hline
\end{tabular}

${ }^{a}$ Estimates reported are marginal effects from probit regressions. Standard errors in parentheses robust against arbitrary heteroskedasticity in the variance-covariance matrix, and clustered at the table level across all specifications.

*** Significant at 1 percent.

** Significant at 5 percent.

* Significant at 10 percent. 
Table A1-2: Information technologies, renewal outcomes, and police officers' characteristics, La Paz, Bolivia, $2009^{a}$

\begin{tabular}{|c|c|c|c|c|}
\hline & $\begin{array}{l}\text { Completed } \\
\text { process }\end{array}$ & $\begin{array}{l}\text { Completed } \\
\text { process }\end{array}$ & $\begin{array}{l}\text { Renewal } \\
\text { time }\end{array}$ & $\begin{array}{l}\text { Renewal } \\
\text { time }\end{array}$ \\
\hline & $(1)$ & $(2)$ & $(3)$ & $(4)$ \\
\hline & $\begin{array}{c}\text { Male } \\
\text { applicants }\end{array}$ & $\begin{array}{l}\text { Female } \\
\text { applicants }\end{array}$ & $\begin{array}{l}\text { Male } \\
\text { applicants }\end{array}$ & $\begin{array}{l}\text { Female } \\
\text { applicants }\end{array}$ \\
\hline Digital renewal process & $\begin{array}{l}0.1223^{* * *} \\
(0.023)\end{array}$ & $\begin{array}{l}0.1260^{* * *} \\
(0.027)\end{array}$ & $\begin{array}{c}-47.5886^{* * *} \\
(2.754)\end{array}$ & $\begin{array}{c}-45.6537^{* * *} \\
\quad(3.718)\end{array}$ \\
\hline Police officer has low tenure at renewal table & $\begin{array}{c}-0.0122 \\
(0.014)\end{array}$ & $\begin{array}{l}0.0089 \\
(0.014)\end{array}$ & $\begin{array}{l}0.3889 \\
(1.082)\end{array}$ & $\begin{array}{c}3.0254^{*} \\
(1.763)\end{array}$ \\
\hline Police officer is low rank & $\begin{array}{l}0.0018 \\
(0.014)\end{array}$ & $\begin{array}{l}0.0073 \\
(0.016)\end{array}$ & $\begin{array}{c}-0.2834 \\
(1.341)\end{array}$ & $\begin{array}{c}-2.6698 \\
(1.792)\end{array}$ \\
\hline Police officer did not go to college & $\begin{array}{l}0.0097 \\
(0.014)\end{array}$ & $\begin{array}{l}0.0076 \\
(0.016)\end{array}$ & $\begin{array}{l}0.4980 \\
(1.786)\end{array}$ & $\begin{array}{l}0.3146 \\
(2.270)\end{array}$ \\
\hline Police officer is a senior ( $>35$ years old) & $\begin{array}{c}-0.0045 \\
(0.013)\end{array}$ & $\begin{array}{c}-0.0258 \\
(0.017)\end{array}$ & $\begin{array}{l}0.4742 \\
(1.313)\end{array}$ & $\begin{array}{l}2.0677 \\
(1.793)\end{array}$ \\
\hline Police officer is a woman & $\begin{array}{c}-0.0043 \\
(0.012)\end{array}$ & $\begin{array}{c}-0.0185 \\
(0.014)\end{array}$ & $\begin{array}{c}-1.5828 \\
(1.379)\end{array}$ & $\begin{array}{l}2.1145 \\
(1.783)\end{array}$ \\
\hline Digital*(Police officer has low tenure at renewal table) & $\begin{array}{c}-0.0126 \\
(0.023)\end{array}$ & $\begin{array}{c}-0.0013 \\
(0.026)\end{array}$ & $\begin{array}{l}1.6685 \\
(2.287)\end{array}$ & $\begin{array}{c}-0.9293 \\
(2.971)\end{array}$ \\
\hline Digital*(Police officer is low rank) & $\begin{array}{c}-0.0223 \\
(0.021)\end{array}$ & $\begin{array}{l}0.0191 \\
(0.023)\end{array}$ & $\begin{array}{l}0.8561 \\
(2.492)\end{array}$ & $\begin{array}{l}1.3386 \\
(2.749)\end{array}$ \\
\hline Digital*(Police officer did not go to college) & $\begin{array}{l}0.0110 \\
(0.022)\end{array}$ & $\begin{array}{r}-0.0197 \\
(0.028)\end{array}$ & $\begin{array}{l}2.8066 \\
(2.455)\end{array}$ & $\begin{array}{l}3.0501 \\
(3.001)\end{array}$ \\
\hline Digital*(Police officer is a senior) & $\begin{array}{c}-0.0154 \\
(0.021)\end{array}$ & $\begin{array}{l}0.0299 \\
(0.023)\end{array}$ & $\begin{array}{l}1.8210 \\
(2.230)\end{array}$ & $\begin{array}{l}0.2713 \\
(2.592)\end{array}$ \\
\hline Digital*(Police officer is a woman) & $\begin{array}{l}0.0206 \\
(0.023)\end{array}$ & $\begin{array}{l}0.0058 \\
(0.032)\end{array}$ & $\begin{array}{l}2.9751 \\
(2.869)\end{array}$ & $\begin{array}{l}3.2942 \\
(3.078)\end{array}$ \\
\hline $\begin{array}{l}\text { Renewal day fixed effects } \\
\text { Renewal table fixed effects }\end{array}$ & $\begin{array}{l}\text { Yes } \\
\text { No }\end{array}$ & $\begin{array}{l}\text { Yes } \\
\text { No }\end{array}$ & $\begin{array}{l}\text { Yes } \\
\text { No }\end{array}$ & $\begin{array}{l}\text { Yes } \\
\text { No }\end{array}$ \\
\hline $\begin{array}{l}\text { Mean of dependent variable among } \\
\text { applicants in manual tables } \\
\text { Observations }\end{array}$ & $\begin{array}{l}0.7175 \\
10,029\end{array}$ & $\begin{array}{c}0.7155 \\
9,513\end{array}$ & $\begin{array}{c}128.55 \\
7,196\end{array}$ & $\begin{array}{c}129.45 \\
6,807\end{array}$ \\
\hline
\end{tabular}

${ }^{a}$ Estimates for the completion of the renewal are marginal effects from probit regressions. Estimates for the time it takes to complete renewal are OLS coefficients. Standard errors in parentheses robust against arbitrary heteroskedasticity in the variance-covariance matrix, and clustered at the table level.

*** Significant at 1 percent.

** Significant at 5 percent.

* Significant at 10 percent. 